\title{
The Development Opportunities and Difficulties of China- Pakistan Economic Corridor in the Construction of the Belt and Road
}

\author{
Haozheng Bian ${ }^{1,{ }^{*},}{ }^{\dagger}$, Xiangyue Wang ${ }^{2, \dagger}$, Zihan $\mathrm{Xu}^{3, \dagger}$, Xinge Zhang $^{4, \dagger}$ \\ ${ }^{1}$ School of Business, University of Connecticut, Storrs, 06269, USA \\ ${ }^{2}$ Eller College, University of Arizona,Tucson, 85721, USA \\ ${ }^{3}$ School of Economics, Capital University of Economics and Business, Bei Jing, 10070, China \\ ${ }^{4}$ School of Foreign Languages, Shandong University of Finance and Economics, Jinan, 250000, \\ China \\ *Corresponding author. Email: Haozheng.bian@uconn.edu \\ tThese authors contributed equally
}

\begin{abstract}
This paper mainly studied the structural transformation of Pakistan's power sector and the internal and external political problems encountered in its development, as well as the solutions. This study found that Pakistan changed from oil to coal to generate electricity, which can resolve its internal power shortage problem in short term. However, the best way later in the cooperation is to develop green energy to match the green economy, such as wind power. The construction of the economic corridor can expand the import and export of goods and personnel exchanges between China and Pakistan, and promote the transit trade with Pakistan. Besides, it would effectively increase China's energy import routes-bypassing the traditional chokepoints of the Malacca Strait and the disputed South China Sea, bringing Middle Eastern oil directly to its southwestern hinterland and reducing dependence on the China-Myanmar oil and gas pipelines under construction. From a broader perspective, the completion of the China-Pakistan Economic Corridor (CPEC) will closely unite countries in South Asia, Central Asia, North Africa and the Gulf through economic and energy cooperation, forming economic resonance and strengthening Pakistan's strategic position as a bridge connecting Eurasia and Africa.
\end{abstract}

Keywords: Power structure; Electricity; Cultural; Politics; and Education.

\section{Introduction}

During his visit to Pakistan in May 2013, Chinese Premier Li Keqiang officially put forward the long-term plan of the China-Pakistan Economic Corridor (CPEC), which is based on assisting Pakistan in infrastructure expansion and upgrade. It aims to promote and deepen bilateral cooperation in the fields of energy, security as well as economy and achieve effective alignment of development strategies. In 2015, China-Pakistan relations were upgraded from a strategic cooperative partnership to an all-weather strategic cooperative partnership. A " $1+4$ " economic cooperation structure will be formed that is led by the China-Pakistan Economic Corridor and focuses on The Gwadar Port, energy and transportation infrastructure and industrial cooperation. This is a key part of China-Pakistan practical cooperation to build a community with a shared future. Through all-round and multi-area cooperation, the CPEC is conducive to closer and stronger China-Pakistan all strategic cooperative partnership. It is not only a model project and flagship project of China's Belt and Road Initiative, but also provides important opportunities for Pakistan's development. At present, the CPEC has achieved its initial results, but at the same time, it still faces many risks and challenges. Only by fully understanding, fully assessing and actively responding to risks can the construction of the corridor achieve substantive results.

Shi and Lu adopted several economic cooperation strategies signed by China and Pakistan, and then analyzed several terrorist incidents to highlight that the Chinese side should be conservative in their cooperation. Shi and Lu analyzed the economic cooperation between the two countries in recent 
years, such as Multan Highway, 46 billion superhighway, Gwadar port, and a series of terrorist attacks, by using macroeconomic analysis and pros and cons analysis. Shi and Lu believe that China and Pakistan are doing their best to take positive measures to promote the construction of the economic corridor, but at the same time, China should maintain a neutral attitude and not interfere too much because of the possible reversal of Pakistan's internal affairs and security situation. It is difficult to judge the prospects of the economic corridor [1]. Downs' study concluded that CPEC coal power generation is driven by joint efforts of both sides. Downs listed the benefits of coal power generation one by one from the aspects of economy, climate environment and peripheral influence and agreed with the coal power generation plan of CPEC. Downs analyzed the official data of CPEC and the national power data and applied the method of macroeconomic analysis to prove the various benefits of coal power generation to Pakistan, but not to plunge Pakistan into debt crisis. The plan is aimed more at improving Pakistan's economic infrastructure to ease its debt crisis, and China can benefit from the revolving funds promised by Pakistan's government [2].

The Islamic Republic of Pakistan and the People's Republic of China have always admired lasting and friendly relations - despite their ideological differences, as their names suggest. Irshad et al. discussed the economic cooperation between China and Pakistan against the background of the growth of China's investment in Pakistan's infrastructure. The China-Pakistan Economic Corridor construction plan has been successfully launched and the two countries have signed a contract on the plan. Challenges in the political, security and economic spheres include political instability and insecurity. However, from the CPEC point of view, China should not tie it to bilateral relations, but consider it in a regional and comprehensive perspective. China should make use of "resilient forces" in energy, transportation and infrastructure, and "flexible forces", such as China-Pakistan think tanks, mass media, educational exchanges and strong cooperation to promote the economic Corridor projects and make plans for the full implementation of the Belt and Road Initiative [3]. The ChinaPakistan Economic Corridor encapsulates many of China's strategic objectives, and therefore cannot be seen merely as a panacea to help Pakistan out of its economic difficulties or solve the problems plaguing its society. The first undeclared but major obstacle is that China and Pakistan have different goals, almost entirely different - China has a larger strategic goal and sees the corridor more as an important stepping stone to global leadership, while Pakistan sees it as just a solution to its economic difficulties [4]. The China-Pakistan Economic Corridor is at the heart of China-Pakistan relations. It is a comprehensive economic cooperation and geostrategic partnership that will transform Pakistan into a transport hub connecting China with Asia, Europe, the Middle East and Africa through The Port of Goward. Apart from hopes and benefits, CPEC has also fallen victim to political tensions and disputes. At the local level, however, this large-scale project faces certain challenges in terms of impact, route feasibility, implementation and India's concerns in the region. Therefore, it intends to first highlight the characteristics of the Belt and Road and CPEC, diplomatic, military and economic relations between the two neighbours, opportunities, threats and challenges, and then regional politics [5].

Since the establishment of diplomatic ties between China and Pakistan, more cooperation has been conducted in political and military areas, but less in society and culture. China and Pakistan are very different in language, ethnicity, culture and even ideology, and follow different economic and political development models markedly. Especially the local state-owned and private enterprises, because of the uneven multinational management level and staff quality, cannot understand the Islamic traditional culture and folk taboo. Failing to understand complex business relations and legal systems, they often bribe government officials, which violates the local religious thought, or even damages China's "no conditions attached" mode of cooperation, the result is moral hazard. The continuous deterioration of the investment environment is a direct threat to the construction of the economic corridor and the economic downturn caused by these geopolitical and cross-cultural conflicts has continued to devalue the rupee, adversely affecting the financing environment. Moreover, state-owned banks have high power but low efficiency, which reduces the efficiency of capital operation [6]. In addition, to some extent, the differences in language and culture in the 
development of modern culture also restrict the cooperation and development of the cultural industry between China and Pakistan. From Pakistan's perspective, with the integration of diverse cultures, Pakistan has accumulated splendid culture, but at the same time, it has gradually caused cultural division and estrangement in the region [7]. In Pakistan's southwestern province of Baluchistan, tribal and sectarian conflict is intertwined with terrorism. If it sticks to its traditional cultural values, Pakistan is vulnerable for the influence of extreme religious thoughts. Taking advantage of the cultural division and isolation, extreme thoughts and terrorism continue to infiltrate, impeding the normal cultural exchanges and cooperation, as well as the development of cultural industries along the economic corridor. It even interferes with the coordinated economic and social development in the region, which cannot maintain economic integrity and social stability [8].

McCartney identified two big principles in China. The Belt and Road Initiative is generously outward looking and its implications for Pakistan are the acquisition of new industrial capacity and technology and greater opportunities to export to China. The WDP is more inward looking, aiming at both import substitution and export promotion to build productive capacity in Western China, particularly in Xinjiang, as part of a wider effort to provide employment and livelihoods that the Chinese government anticipates will cool ethnic and religious conflict in the province [9]. Alam et al. analyzed the impact of transport cost and travel time on trade under China-Pakistan Economic Corridor. Qualitative statistics and descriptive statistics were used to compare the existing route and the new route of CPEC. The variables (transportation cost and travel time) of the existing route and the new CPEC route are calculated and compared. It found that the shipping industry plays a vital role in the development of trade, and about $90 \%$ of world trade is carried by the international shipping industry. Without shipping, large-scale import and export of goods would be impossible. [10]. Chaudhry, et al. specifically examined the influence of CPEC on fruits export of Pakistan. Some of the basic determinations of China-pakistan Economic Corridor are to boost business opportunities, efficient transport routes and expand regional trade. They analysed the CPEC's impact on exports. especially exports from fruit market of Pakistan, by using Gravity Approach for the evaluation of this bilateral trade. The results show that CPEC reduces distance and it will be more beneficial for perishable goods trade like fruits [11].

This study discussed the outcomes of China and Pakistan's infrastructure transformation through CPEC cooperation, especially in the power sector. Then it analyzed the difficult factors of ChinaPakistan cooperation, including internal and external political factors, cultural differences, education level and other issues. It also countered the Chinese conspiracy theory by pointing out the achievements of China's help in Pakistan's construction. Although there are many difficulties in China-Pakistan cooperation, this study provided many appropriate solutions for reference.

\section{Pakistan's development opportunity in electricity and further explain}

\subsection{National view}

China decided to help Pakistan develop infrastructures. One of the most significant fields is Power Project. Before China got involved in Pakistan's power production, the main raw resource for producing electricity was petroleum. After China helped Pakistan develop new electronic infrastructure, the main related source changed to coal, so many people are concerned that coal's burning would release too much $\mathrm{CO}_{2}$ leading to the greenhouse effect. This worry has its points, but it is not totally correct, for nowadays China is committed to developing all new energy sources to achieve the goal of building a green Belt and Road. Considering the countryside of Pakistan, it is impossible to reach this goal in a short term. The only thing Pakistan can do is to reduce its debts and find a better alternative source instead of petroleum. Contrary to this fear, Pakistan has benefited greatly from the transformation of electricity production. The main purpose of coal power generation is to solve Pakistan's power deficit as soon as possible and to help alleviate the economic losses caused by the lack of electricity. The utilization of coal for power generation is not direct for a long time. Considering long-term ecological problems, the CPEC plan is expected to change the power 
structure of Pakistan from mainly relying on coal to relying on green energy, including natural gas and hydroelectric power generation.

China has only promoted and helped Pakistan to use coal for power generation, which is a domestic decision, and this project has largely helped Pakistan to ease internal pressures without causing environmental problems. It is clear from the chart that from 2020 to 2030, Pakistan's power projects will change further to become greener and national. This is the initial foundation for the infrastructure of Pakistan and the beginning of Pakistan's development.

\subsection{Local View}

Table 1. China-Pakistan Energy Project [4]

\begin{tabular}{|c|c|c|c|}
\hline Project & Project Name & Status & Completion \\
\hline 1 & $2 * 660 \mathrm{MW}$ & Under Construction & $100 \%$ \\
\hline 2 & $2 * 660 \mathrm{MW}$ Sahiwai Coal-Fired Power Plant & Two units inaugurated & $100 \%$ \\
\hline 3 & $\begin{array}{c}\text { Thar Coal-fired Power Plant and Surfice Mine } \\
\text { in Block II of Thar Coal Field }\end{array}$ & Under Construction & $60 \%$ \\
\hline 4 & 50MW Dawood Wind Farm & $\begin{array}{l}\text { Commercial Operation } \\
\text { Date achieved }\end{array}$ & $100 \%$ \\
\hline 5 & $\begin{array}{c}\text { 900MW Quaid-e-Azam Solar Park in } \\
\text { Bahawalpur }\end{array}$ & Energization achieved & $100 \%$ \\
\hline 6 & 100MW Jhimpir Wind Farm & Under Construction & $100 \%$ \\
\hline 7 & 873MW Suki Kinari Hydropower Project & Under Construction & $65 \%$ \\
\hline 8 & 50MW Sachai Wind Farm & $\begin{array}{l}\text { Commercial Operation } \\
\text { Date Achieved }\end{array}$ & $100 \%$ \\
\hline 9 & 2*660MW Rahimyar Khan Coal Power Plant & Feasibility Stage & $15 \%$ \\
\hline 10 & $\begin{array}{c}\text { Thar Coal Block I and } 2 * 660 \mathrm{MW} \text { Mine Mouth } \\
\text { Power Plant }\end{array}$ & To be inaugurated & $50 \%$ \\
\hline 11 & $2 * 660 \mathrm{MW}$ Hubco Coal power Plant & $\begin{array}{l}\text { Implementation Agreement } \\
\text { Initiated }\end{array}$ & $50 \%$ \\
\hline 12 & 300 MW Gwadar Power Plant & Feasibility Stage & $60 \%$ \\
\hline 13 & Matiari-Lahore Transmission Line & Negotiation In Process & $15 \%$ \\
\hline 14 & Matiari-Faisalabad Transmission Line & Negotiation In Progress & $15 \%$ \\
\hline 15 & $\begin{array}{c}2 * 660 \mathrm{MW} \text { Gaddani Powerplant at District } \\
\text { Lasbela, Balochistan }\end{array}$ & Feasibility Stage & $15 \%$ \\
\hline 16 & $\begin{array}{c}2 * 660 \mathrm{MW} \text { Muzaffargarh Coal-fired Power } \\
\text { Plant }\end{array}$ & Feasibility Stage & $15 \%$ \\
\hline
\end{tabular}

With the development of CPEC, the level of local infrastructure in Pakistan has also increased, and the corresponding living standards of the people are getting increasingly better. The CPEC has also brought a lot of opportunities to the local people. However, some scholars believe that the benefits of the corridor are mainly in urban areas, and people in some remote areas do not benefit 
much. In four provinces of Pakistan, rural areas lack basic facilities, such as hospitals, schools, industries and irrigation, and housing facilities are relatively poor. The $35 \%$ of Pakistan's rural population lives below the subsistence level without social services, and more than $64 \%$ of women live in rural areas [4]. The social status of women is low in a patriarchal society like Pakistan. Every year, a large number of women are assaulted, and they are discriminated against in their daily lives and in their search for work. However, the Chinese and Pakistani governments are gradually dealing with a large number of problems in rural areas. The Chinese government issued several decrees to address poverty in rural areas, such as the "Disciplinary Regulations of the Communist Party of China". It also began to shift the focus of development to parts of the countryside to improve the local infrastructure and electricity supply. In Rahimyar Khan province, the government is investing \$16 million in a coal power project to provide electricity to Rahimyar Khan province and surrounding rural areas. There are countless such projects that invest in poor areas. The table one shows some of the projects that China has invested in.

These various projects in Table 1 reveal that China is working hard to help improve the living conditions and provide opportunities in the poorer areas of rural Pakistan.

\section{Risks and challenges to be addressed in building the CPEC}

\subsection{Economics}

Pakistan's economic development level is relatively backward, which is still a low- and middleincome country with low global competitiveness. Although Pakistan is the second largest country in South Asia after India, and its GDP in the Silk Road Economic Belt is in the upper middle level, according to the statistical data of the World Bank, Pakistan's GDP in 2014 was just $\$ 244.361$ billion, which ranked it as a low- and middle-income country [12].

Industry, especially manufacturing, is relatively backward in Pakistan. According to the statistics of the World Bank, the proportion of Pakistan's manufacturing industry in the total industrial output value has been around $13 \%$ for a long time, which is not only lower than India in South Asia, but also lower than Bangladesh and Sri Lanka. The backward industrial and manufacturing level is not conducive to industrial cooperation between China and Pakistan.

\subsection{Pakistan's Domestic Political Situation is Difficult to Stabilize}

After the founding of the People's Republic of Pakistan, the political situation in Pakistan has been struggling with military intervention and political party struggle. Although a smooth transition of elected government was achieved in May 2013, Sharif, who took power for the third time, was still unable to maintain political stability. For example, in 2014, Pakistan's two main opposition parties, the Tehreek-e-Insaf and the Awami Movement Party, have staged lengthy and widespread demonstrations calling for Prime Minister Sharif to step down and administrative reforms. This political storm has seriously challenged the ruling ability of the current government. It is not difficult to predict that the political ecology in Pakistan will have a great negative impact on the construction of CPEC.

Besides, there is fierce competition for interests among different local tribes. In Pakistan, there is a dispute over the route of CPEC construction. The Khyber-Pakhtunkhwa and Baluchistan provinces advocate a "western route", which starts from Kashgar in the north, enters Pakistan via the Khunjirab Pass, and then runs along the Karakoram Highway to Gilgit-Baltistan in Pakistan-administered Kashmir, through Khyber-Pakhtunkhwa province to Gwadar Port in Baluchistan. Pakistan's government has pushed for an "eastern front" through Punjab, sparking a series of controversies. The dispute over the route for the construction of CPEC is actually a battle of interests among different parties and tribes. 


\subsection{Sociocultural Dimensions (China and Pakistan)}

As for China, the cultivation of talents in Urdu (the official language of Pakistan) is lagging behind, which deteriorates the progress of cooperation. Moreover, the education level of China is much better than that of Pakistan. In the process of cultural industry cooperation, it is difficult to maintain the quality of human capital required by the manufacturing of cultural products and the provision of cultural services, which will hinder the sustainable cooperation and thus produce a series of potential risks.

Therefore, it is necessary to deepen conceptual identity and enhance cultural mutual trust in the construction of CPEC. The two sides should promote mutual visits of leaders at all levels, actively build platforms for exchanges, and stimulate interest in mutual understanding and friendship by holding cultural fairs, building cultural exchange centers or holding cultural festivals. Meanwhile, deepening cooperation on education is another way to enhance cultural understanding. While strengthening the construction of existing Confucius Institutes, China has responsibility to increase funding for Pakistani students to study in China and train reserve talents for the CPEC.

\subsection{External Geopolitical Competition}

In the process of continuous progress, it is inevitable to touch nerves of many parties, and provoke related countries, such as India and the United States, to participate in the geopolitical game.

Indian Prime Minister Narendra Modi revoked Indian-administered Kashmir's self-governing status on Aug.5, 2020, a move that has heightened tensions between India and Pakistan, inflaming tensions in South Asia and hampering economic cooperation in the region. Because the CPEC runs through POK and India does not recognize the way the border is drawn, it is also strongly opposed to the CPEC plan, even to set up a think tank and institute for CPEC and to put forward special countermeasures. During his visit to China in 2015, Modi made a point of telling Beijing that India "cannot accept" the CPEC project. Modi also questioned China's intention to build the corridor, arguing that China and Pakistan are not working together for economic benefits, but to contain India's influence in South Asia and the Indian Ocean region.

For a long time, western countries have been sticking to the "Cold War" and "zero-sum game" mentality led by the United States, pointing fingers and creating trouble in many sensitive areas of the world. Western countries, led by the US, frequently stir up trouble in the region, and even put forward their so-called "New Silk Road" plan to incite Pakistan to join with the aim of isolating China. This is interfering with the cooperation between the two countries and stealing the fruits of China's development. Moreover, the United States has intensified its own cultural and ideological indoctrination, which has led many Pakistanis, especially the young, to become pro-European and pro-beautify. In addition, China's image has been arbitrarily discredit. Therefore, it has also increased the difficulties of cultural exchanges between China and Pakistan.

While maintaining official exchanges, both China and Pakistan are required to carry out targeted exchanges in folk culture and expand the Chinese language in order to further establish a positive image of China among the Pakistani people and increase their favorable impression on China. As the Gwadar Port, China-Pakistan energy cooperation and the completion of a number of early projects in Pakistan's infrastructure developing, Pakistan's social and economic development has been boosted. In the next stage, it is time for the two countries to expand their development to the areas of people's consciousness.

\section{Relevant countermeasures and suggestions}

With regard to policy thinking on promoting the Construction of China-Pakistan Economic Corridor, although the CPEC faces some challenges, China and Pakistan are full of confidence in its prospects. The CPEC is seen as a catalyst for Pakistan's economic development by domestic and international investors and has become the main attraction for Investment in Pakistan. Pakistani businessmen have recognized that CPEC will boost their country's prosperity and businessmen in 
Lahore and Karachi have begun to seek long-term financial support from banks to participate in supporting projects of CPEC in large and medium scale.

The CPEC project will also provide a large number of jobs for Pakistan. In the long run, the CPEC, especially the construction of roads, railways and industrial parks along the central and western routes, will change the economic geography of Pakistan, promote the development of the tribal areas in the central and western regions and consolidate the unity of the country. The CPEC will connect Central Asia, Afghanistan, Iran, India and China. It will change the interconnectivity between Central and South Asia and the fragmentation of the regional economic integration process in South Asia. As a result, there is little opposition to CPEC in Pakistan, although there are disputes over the route of CPEC.

The enthusiasm of the Chinese and Pakistani governments and people for the CPEC fully demonstrates the profound friendship between China and Pakistan, as well as Pakistan's urgent desire to cooperate with China to promote economic and social development.

However, enthusiasm alone is far from enough for the CPEC to be completed. It is also necessary for the governments and peoples of the two countries to actively create a favorable internal and external environment for the construction of the CPEC. Ultimately, it will mainly depend on the concrete implementation of the project and the solidarity and hard work spirit of the people of the two countries, especially Pakistan. At present, Prime Minister Nawaz Sharif and his administration have high hopes for accelerating economic development through cooperation with China. They realize that to eliminate terrorism fundamentally, the government also needs to develop economy and improve people's living standards and happiness index. Sharif and his party have rich experience in national governance and economic development and are willing to unite with other parties in Pakistan to seek common interests. Therefore, the period of former Prime Minister Nawaz Sharif's rule in 2018 can be seen as a strategic opportunity to push forward the construction of CPEC.

\section{Conclusion}

The Belt and Road is a modern link of trade and communication between east and West. For China, the Belt and Road is the great road of rejuvenation for China's strategic development. It is not only an extension of the ancient Silk Road, but also represents the connotation and strategic significance of the new era. In the process of the belt and Road development, China has gradually realized the Chinese dream and played a leading role in promoting the development of the world economic community. Although the belt and Road is still a long way off and there are many opportunities and challenges, it should be believed that through the unremitting efforts of multiple parties, more efforts should be made in eliminating terrorism, ensuring a safe environment for construction at home and abroad and expanding industrial development in the belt and Road regions. The economic strategy will be a historic, pioneering and great cooperation outcome.

\section{References}

[1] Zhiqin, S., \& Yang, L. (2016). The Benefits and Risks of the China-Pakistan Economic Corridor. Carnegie-Tsinghua Center for Global Policy, December 21.

[2] Downs, E. (2019). China-Pakistan Economic Corridor Power Projects: Insights into Environmental and Debt Sustainability. New York: Center on Global Energy Policy, Columbia University.

[3] Irshad, M. S., Xin, Q., \& Arshad, H. (2015). One Belt and One Road: Does China-Pakistan Economic Corridor benefit for Pakistan's Economy? Journal of Economics and Sustainable Development, 6 (24), $200-207$.

[4] Ranade, J. (2017). Does the China-Pakistan Economic Corridor Really Help Pakistan? Liberal Studies, 2 (1), $33-41$.

[5] Ishaq, M., Ping, R. J., \& Ahmed, B. (2017). Pakistan-China Economic Corridor (CPEC): Opportunities, Threats and Challenges. International Affairs and Global Strategy, 52, 9- 16. 
[6] Shaikh, F., Ji, Q., \& Fan, Y. (2015). The diagnosis of an electricity crisis and alternative energy development in Pakistan. Renewable and Sustainable Energy Reviews, 52, 1172 - 1185.

[7] Saad, A., Ijaz, M., Asghar, M., \& Yamin, L. (2020, October 2). China-Pakistan economic corridor and its impact on rural development and human life SUSTAINABILITY. observations from rural women. Retrieved September 07, 2021, from.

[8] Zhang, M. (2019) Construction of China-Pakistan Economic Corridor: Achievements, risks and countermeasures. Journal of Northwest University, 17.

[9] McCartney, M. (2020). The Prospects of the China-Pakistan Economic Corridor (CPEC): The Importance of Understanding Western China. Contemporary South Asia, $1-18$.

[10] Alam, K. M., Li, X., \& Baig, S. (2019). Impact of Transport Cost and Travel Time on Trade under ChinaPakistan Economic Corridor (CPEC). Journal of Advanced Transportation, 2019, 1 - 16.

[11] Chaudhry, I. S., Gulzar, F., Ahmad, H. G., \& Rahman, S. ur. (2017). Impact of China-Pakistan Economic Corridor (CPEC) on Pakistan's Trade: Empirical Evidence from Gravity Model. Review of Economics and Development Studies, 3 (1), 29 - 38.

[12] https://m.gotohui.com/gdp-3452. 